\title{
KORELASI PESAN DENGAN SIKAP PESERTA PENYULUHAN PROGRAM KELUARGA BERENCANA NASIONAL DI PUSKESMAS PEMBANTU
}

\section{MESSAGE CORRELATION WITH ATTITUDE PARTICIPANTS OF FAMILY PLANNING PROGRAM NATIONAL PLANNING IN HEALTH CENTER}

\author{
MR Maulida1a, Sukarelawati², AA Kusumadinata ${ }^{3}$ \\ 1,2,3 Jurusan Ilmu Komunikasi, Fakultas Ilmu Sosial dan Ilmu Politik, Universitas Djuanda \\ Jl. Tol Ciawi No.1 Kotak Pos 35 Bogor 16720.
}

1aKorenpondensi: Mia Rizky Maulida, Email: rizkymia12@gmail.com

(Diterima: 5-8-2017; Ditelaah: 19-8-2017; Disetujui: 27-9-2017)

\begin{abstract}
The extension messages consist of spoken messages, which include the definition of family planning, the purpose of family planning, the benefits of family planning, types of contraceptives, and supporting messages (non verbal), which include agency logos, brochures and teaching aids. With the counseling message will change the attitude, which consists of cognitive, affective, and behavioral. This research was conducted in RT 02 RW 01 Kelurahan Cilendek Timur, Bogor Regency. The time of the research was conducted in August 2016 until September 2017. The analysis of variables in this study using quantitative analysis, that is with statistics. Once the data is collected completely, the next step is to analyze the data. The results showed that for the indicator of the spoken message and the message of support (non verbal) have a real relationship with the attitude of the extension participants.
\end{abstract}

Keywords: Message, Attitude, Family Planning National Program

\begin{abstract}
ABSTRAK
Pesan penyuluhan terdiri dari pesan yang diucapkan, yang meliputi pengertian KB, tujuan KB, manfaat $\mathrm{KB}$, jenis-jenis alat kontrasepsi, serta pesan pendukung (non verbal), yang meliputi logo lembaga, brosur, dan alat peraga penyuluhan. Dengan adanya pesan penyuluhan tersebut akan mengubah sikap, yang terdiri dari kognitif, afektif, dan behavioral. Penelitian ini dilakukan di RT 02 RW 01 Kelurahan Cilendek Timur, Kabupaten Bogor. Waktu penelitian dilakukan pada Agustus 2016 sampai dengan bulan September 2017. Analisa variabel dalam penelitian ini menggunakan analisa kuantitatif, yaitu dengan statistik. Setelah data terkumpul dengan lengkap, langkah selanjutnya adalah menganalisis data. Adapun hasil penelitian menunjukkan bahwa untuk indikator pesan yang diucapkan dan pesan pendukung (non verbal) mempunyai hubungan nyata dengan sikap peserta penyuluhan.
\end{abstract}

Kata Kunci : Pesan, Sikap, Program Keluarga Berencana Nasional

Korelasi Pesan dengan Sikap Peserta Penyuluhan Program Keluarga Berencana Nasional di Puskesmas Pembantu

MR Maulida, Sukarelawati, AA Kusumadinata. 2017. Korelasi Pesan dengan Sikap Peserta Penyuluhan Program Keluarga Berencana Nasional di Puskesmas Pembantu. Jurnal Komunikatio 3(2): 83-94. 


\section{PENDAHULUAN}

Berdasarkan hasil sensus yang dilakukan oleh Dinas Kependudukan dan Pencatatan Sipil Kota Bogor pada bulan September 2015, jumlah penduduk di Kelurahan Cilendek Timur adalah 9.258 jiwa dengan jumlah lakilaki 4.737 dan perempuan 4.521 (Dinas Kependudukan dan Catatan Sipil Kota Bogor 2015) .

Dari tahun ke tahun jumlah penduduk mengalami peningkatan, kini jumlah penduduk di Kelurahan Cilendek Timur meningkat $2 \%$ dari tahun sebelumnya. Hal ini menjadi permasalahan, karena dengan meningkatnya jumlah penduduk di Kelurahan Cilendek Timur membuat desa tersebut menjadi padat penduduk. Selain masalah kepadatan penduduk, di Kelurahan Cilendek Timur sendiri timbul masalah dalam bidang pendidikan, dimana angka putus sekolah yang terjadi cukup tinggi. Dari data yang diperoleh di Kelurahan Cilendek Timur terdapat sekitar 59 anak yang putus sekolah dengan jenjang pendidikan hanya sampai sekolah dasar (Kelurahan Cilendek Timur 2016, Hasil Observasi dan Wawancara)

Gambaran di atas menjadi suatu masalah besar, karena berbeda dengan negara maju yang memiliki jumlah penduduk yang banyak, tetapi sebagian besar penduduknya memiliki kualitas yang baik. Saat ini kualitas penduduk Indonesia umumnya masih rendah, tercermin dari tingkat pendidikan, dimana hampir 2/3 penduduk berpendidikan dibawah SMP. Kualitas sumber daya manusia Indonesia yang masih sangat rendah ini meningkatkan beban kepala negara karena ledakan jumlah penduduk ini akan bertambah luas terhadap penyediaan anggaran dan fasilitas kesehatan, pendidikan, serta ketersediaan pangan. Ledakan jumlah penduduk ini pun akan berdampak terhadap pemenuhan gizi baik serta meningkatnya angka pengangguran (https://catherine maname.wordpress.com diakses tanggal 25 Desember 2016).

Berkaitan dengan penyuluhan $\mathrm{KB}$ yang akan dilakukan di Cilendek Timur, maka faktor yang akan disuluhkan merupakan hal penting, sehingga perlu direncanakan dengan matang agar isi pesan dapat dipahami hingga menimbulkan pemaknaan pada diri sasaran ke arah kognitif, afektif, atau behavior. Melalui desain visual atau cara penyampaian langsung isi pesan kepada sasaran penyuluhan, maka pesan penyuluhan perlu menggambarkan permasalahan yang relevan bagi sasaran. Pesertanya pun sesuai dengan target penyuluhan, dengan tujuan agar sasaran mampu memahami pemaknaan pesan, yang dilaksanakan melalui pendekatan langsung dan media pendukung seperti teks (materi) penyuluhan.

Dengan demikian akan diketahui bagaimana pengembangan pesan oleh komunikator pada proses penyuluhan sebagai bentuk sosialisasi dimungkinkan akan menimbulkan pemaknaan yang berbeda kepada komunikan sesuai dengan kondisi dan situasi peserta penyuluhan (komunikan) pada ranah sikap seperti kognitif, afektif atau behavioral. Pada konteks pengembangan pesan dapat dilihat dari materi berikut permasalahan yang terkandung dalam materi penyuluhan, juga simbol-simbol pendukung secara non verbal dari pesan penyuluhan yang disampaikan pada saat penyuluhan.

Efektivitas komunikasi dalam kegiatan penyuluhan dilihat dari sejauh mana kegiatan tersebut mampu mengubah sikap pesertanya. Sikap dalam hal ini berarti konstelasi komponen-komponen kognitif, afektif, dan behavioral yang saling berinteraksi dalam pemahaman atau pemaknaan awal saat sasaran penyuluhan menerima rangsangan dari objek isi pesan, sehingga berkembang ke arah perasaan dan berperilakunya terhadap suatu objek. Azwar (2005) membagi sikap menjadi tiga komponen yaitu komponen kognitif, adalah komponen yang terdiri dari pengetahuan; komponen afektif, adalah komponen yang berhubungan dengan perasaan senang atau tidak senang; komponen konatif, adalah komponen sikap yang berupa kesiapan seseorang untuk berperilaku yang berhubungan dengan objek sikap. Sikap masyarakat tersebut akan dipengaruhi juga oleh materi penyuluhan yang disampaikan oleh penyuluh. Materi penyuluhan program KB meliputi pengertian keluarga berencana, 
tujuan keluarga berencana, manfaat keluarga berencana, dan jenis-jenis alat kontrasepsi (Prawirohardjo, 2003). Selain itu, perlu pula diperhatikan pesan pendukung (non verbal) berupa logo lembaga, brosur dan alat peraga penyuluhan. Adapun kegiatan penyuluhan program Keluarga Berencana Nasional dilaksanakan 2-3 kali dalam sebulan oleh Petugas Puskesmas Pembantu Cilendek Timur.

Dalam kegiatan penyuluhan program $\mathrm{KB}$ Nasional pada masyarakat Kelurahan Cilendek Timur dilakukan dengan penyuluhan langsung. Dengan penyuluhan langsung, diharapkan mudah diterima, khususnya bagi masyarakat Kelurahan Cilendek Timur. Berdasarkan pemaparan di atas, peneliti tertarik untuk mencari tahu hubungan pemaknaan materi penyuluhan dengan sikap peserta penyuluhan program Keluarga Berencana Nasional yang diselenggarakan oleh Puskesmas Pembantu Cilendek Timur. Berdasarkan hal tersebut, maka penulis ingin meneliti lebih jauh mengenai korelasi pesan dengan sikap peserta penyuluhan program keluarga berencana nasional di Puskesmas Pembantu Cilendek Timur.

Tujuan yang diharapkan dari penelitian yang dilakukan ini adalah (1) Mengidentifikasi pesan penyuluhan program Keluarga Berencana Nasional di Puskesmas Pembantu Cilendek Timur,

Mengidentifikasi sikap peserta penyuluhan program Keluarga Berencana Nasional Puskesmas Pembantu Cilendek Timur, (3) Menganalisis hubungan antara pesan penyuluhan dengan sikap peserta penyuluhan program Keluarga Berencana Nasional Puskesmas Pembantu Cilendek Timur.

Penelitian ini diharapkan dapat memberikan sumbangan bagi pendidikan komunikasi dan memperkaya hasil penelitian yang telah ada, serta dapat menambah pengetahuan dan wawasan bagi pembaca khususnya pada kajian mengenai hubungan antara pemahaman materi penyuluhan dengan sikap peserta penyuluhan program Keluarga Berencana Nasional. Selain itu, penelitian ini diharapkan dapat membantu penyusunan program penyuluhan Puskesmas Pembantu Cilendek Timur yang tepat bagi sasaran, khususnya untuk mengikuti program keluarga berencana.

\section{Tinjauan Teori}

Metode sosialisasi yang digunakan dalam penelitian ini adalah melalui komunikasi tatap muka yang berupa penyuluhan langsung dipadukan dengan pesan pendukung pada program KB Nasional oleh Puskesmas Pembantu Cilendek Timur kepada masyarakat sebagai peserta program. Sebagaimana telah dijelaskan sebelumnya bahwa keberhasilan penyebaran informasi dalam rangka penyuluhan program $\mathrm{KB}$ ke arah perubahan sikap dikalangan masyarakat sasaran, sehingga diharapkan mereka tahu, mau dan mampu melakukan perubahan demi tercapainya peningkatan produksi, pendapatan atau keuntungan dan perbaikan kesejahteraannya (Subejo, 2010).

Pesan pendukung dalam penelitian ini meliputi :

1. Logo lembaga

Logo merupakan suatu hal yang nyata sebagai pencerminan hal-hal yang bersifat non visual dari suatu perusahaan, misalnya budaya perilaku, sikap, kepribadian, yang dituangkan dalam bentuk visual (Suwardikun, 2000) Logo dapat juga disebut dengan simbol, tanda gambar, merek dagang (trademark) yang berfungsi sebagai lambang identitas diri dari suatu lembaga dan tanda pengenal yang merupakan ciri khas lembaga tersebut.

2. Brosur

Brosur merupakan buku kecil yang tipis yang berisikan keterangan mengenai suatu hal atau kegiatan (Effendy, 1989). Brosur adalah selebaran yang berisi mengenai tiga fungsi, yaitu fungsi informatif, fungsi iklan, dan fungsi identifikasi dimana antara fungsi yang satu dengan fungsi yang lain sangat berkaitan untuk proses presentasi program KB. Secara fungsi mendasar brosur dapat diwakili oleh sebuah kartu nama, namun brosur lebih menginformasikan secara luas dan detail mengenai maksud dan tujuan sesuai dengan isi brosur tersebut seperti penjelasan tentang suatu produk, layanan, 
fasilitas umum, profil perusahaan, sekolah, atau dimaksudkan sebagai sarana beriklan. Informasi dalam brosur KB di Puskesmas Pembantu Cilendek Timur ditulas dalam bahasa yang ringkas dan jelas agar mudah dipahami dalam waktu yang singkat dan brosur juga didesain agae menarik perhatian peserta penyuluhan keluarga berencana, lebih menginformasikan secara luas dan detail mengenai maksud dan tujuan sesuai dengan isi brosur tersebut.

3. Alat peraga penyuluhan

Merupakan peralatan yang digunakan dalam proses penyuluhan, meliputi alat multimedia peraga, layar, laptop dan alat kontrasepsi KB. Alat peraga penyuluhan adalah alat-alat yang digunakan oleh penyuluh dalam menyampaikan informasi. Alat peraga berfungsi untuk membantu

\section{METODE PENELITIAN}

Pendekatan yang digunakan dalam penelitian ini adalah deskriptif kuantitatif. Menurut Nawawi (2003) metode deskriptif yaitu metode-metode penelitian yang memusatkan perhatian pada masalah-masalah atau fenomena yang bersifat aktual pada saat penelitian dilakukan, kemudian menggambarkan fakta-fakta tentang masalah yang diselidiki sebagaimana adanya diiringi dengan interprestasi yang rasional dan akurat. Dengan demikian, penelitian ini akan menggambarkan fakta-fakta dan menjelaskan keadaan dari objek penelitian berdasarkan fakta-fakta dan menjelaskan keadaan dari objek penelitian berdasarkan fakta-fakta yang ada dan mencoba menganalisis kebenarannya berdasarkan data yang diperoleh.

Penelitian ini menggunakan metode penelitian kuantitatif yang bersifat deskriptif korelasional, karena metode ini menggunakan tabel-tabel atau gambar, sehingga data lebih mudah dibaca dan dideskripsikan. Metode ini juga dimaksudkan untuk menguji hubungan antara pesan penyuluhan dengan sikap peserta penyuluhan program Keluarga Berencana Nasional. dan meragakan sesuatu dalam proses penyuluhan (Notoatmodjo, 2007).

Pembentukan sikap tidak terjadi dengan sendirinya atau terjadi begitu saja. Pembentukannya selalu berhubungan dengan interaksi sosial baik yang terjadi di dalam maupun di luar kelompok, baik berjalan secara alamiah maupun dengan bantuan teknologi informasi. Pada dasarnya proses pembentukan sikap berawal dari lingkungan keluarga, kemudian interaksi dengan lingkungan masyarakat dan tentu saja berhubungan dengan lingkungan pendidikan, baik formal maupun informal. Selain itu sikap juga berhubungan dengan perbedaan bakat, minat, intensitas perasaan (Azhari, 2004). Berkaitan dengan penelitian, pembentukan sikap dilihat dari sikap sasaran pada penyuluhan program KB Nasional di Puskesmas Pembantu Cilendek Timur.

Unit analisis dalam penelitian ini adalah populasi dan sampel, yaitu masyarakat RT 02 RW 01 Kelurahan Cilendek Timur, Kabupaten Bogor. Populasi dalam penelitian ini adalah peserta penyuluhan program KB Nasional. Data yang diperoleh dari Puskesmas Pembantu Cilendek Timur sampai dengan bulan Juni 2016, peserta penyuluhan program penyuluhan KB Nasional di RT 02 RW 01 adalah sebanyak 56 orang. Selanjutnya, teknik sampling yang akan digunakan dalam penelitian ini adalah teknik sampling jenuh atau sampel sensus, yaitu mengambil seluruh populasi yang ada sebagai sampel yang diperlukan guna mendapatkan informasi atau data. Peneliti memilih menggunakan teknik sampel jenuh karena menurut Sugiyono (2012) sampel jenuh merupakan teknik penentuan sampel bila semua anggota populasi digunakan sebagai sampel. Hal ini sering dilakukan bila jumlah populasi relatif kecil atau penelitian yang ingin membuat generalisasi dengan kesalahan yang sangat kecil. Dari data yang diperoleh diketahui bahwa peserta program penyuluhan KB Nasional di RT 02 RW 01 adalah sebanyak 56 orang. Dengan demikian, jumlah sampel dalam penelitian ini adalah 56 orang. 
Data yang digunakan dalam penelitian ini adalah data primer dan data sekunder. Sedangkan teknik yang digunakan untuk mengumpulkan data dalam penelitian ini adalah studi kepustakaan dan studi lapangan.

Teknik analisis data dalam penelitian kuantitatif menggunakan statistik. Pada penelitian ini teknik statistik yang digunakan untuk analisis data penelitian yaitu statistik deskriptif dan analisis statistik non parametrik. Statistik deskriptif digunakan untuk mendeskripsikan data sampel yang telah diperoleh. Analisis statistik deskriptif tidak dibuat kesimpulan yang berlaku untuk populasi dimana sampel diambil. Analisis deskriptif dilakukan dengan mencari frekuensi dan persen. Kesimpulan dibuat dengan

\section{HASIL DAN PEMBAHASAN}

\section{Pesan Penyuluhan Program Keluarga Berencana Nasional}

Pesan penyuluhan program Keluarga Berencana Nasional di Puskesmas Pembantu Cilendek Timur dapat diketahui melalui indikator-indikatornya, yaitu pesan yang diucapkan, yang meliputi pengertian $\mathrm{KB}$, tujuan $\mathrm{KB}$, manfaat $\mathrm{KB}$, dan jenis-jenis alat kontrasepsi, serta pesan pendukung (non menggunakan teknik analisis statistik non parametrik, dengan melakukan hubungan antara pesan penyuluhan dengan sikap peserta penyuluhan program Keluarga Berencana Nasional. Pengujian hubungan pada penelitian ini dilakukan dengan mengunakan SPSS 21 for Windows.

Pengujian hipotesis melalui dua sudut pandang, yaitu berdasarkan nilai koefisien korelasi Rank Spearman (rs) $\mathrm{rs}_{\text {hitung }}>\mathrm{rs}_{\text {tabel }}=$ tolak Ho, hipotesis benar, $\mathrm{rs}_{\text {hitung }}<\mathrm{rs}_{\text {tabel }}=$ terima Ho, hipotesis salah, dan melalui $p$ value jika nilai signifikansi $>0,05$ artinya berhubungan nyata pada taraf $\alpha 0,05$ dan nilai signifikansi $>0,01$ artinya sangat berhubungan nyata pada taraf $\alpha 0,01$.

verbal), yang meliputi logo lembaga, brosur dan alat peraga penyuluhan.

Berdasarkan hasil penyebaran kuesioner terhadap 56 responden yang merupakan peserta penyuluhan program Keluarga Berencana Nasional, dapat diketahui pesan penyuluhan program Keluarga Berencana Nasional di Puskesmas Pembantu Cilendek Timur, sebagai berikut : 
Tabel 1 Tanggapan Responden Mengenai Pesan Penyuluhan Program Keluarga Berencana Nasional

\begin{tabular}{|c|c|c|c|}
\hline Indikator & Jawaban & $\begin{array}{c}F \\
\text { (Orang) }\end{array}$ & $\begin{array}{c}\text { Persen } \\
(\%)\end{array}$ \\
\hline \multicolumn{4}{|l|}{ Pesan yang diucapkan } \\
\hline \multirow[t]{6}{*}{ Pengertian KB } & SS & 6 & 10,71 \\
\hline & $\mathrm{S}$ & 30 & 53,57 \\
\hline & $\mathrm{CS}$ & 17 & 30,36 \\
\hline & TS & 3 & 5,36 \\
\hline & STS & 0 & 0,00 \\
\hline & Jumlah & 56 & 100 \\
\hline \multirow{6}{*}{ Tujuan KB } & SS & 12 & 21,42 \\
\hline & $\mathrm{S}$ & 29 & 51,79 \\
\hline & $\mathrm{CS}$ & 15 & 26,79 \\
\hline & TS & 0 & 0,00 \\
\hline & STS & 0 & 0,00 \\
\hline & Jumlah & 56 & 100 \\
\hline \multirow[t]{6}{*}{ Manfaat KB } & SS & 7 & 12,50 \\
\hline & $\mathrm{S}$ & 28 & 50,00 \\
\hline & $\mathrm{CS}$ & 19 & 33,93 \\
\hline & TS & 2 & 3,57 \\
\hline & STS & 0 & 0,00 \\
\hline & Jumlah & 56 & 100 \\
\hline \multirow[t]{6}{*}{ Jenis-jenis alat kontrasepsi } & SS & 5 & 8,93 \\
\hline & $\mathrm{S}$ & 34 & 60,71 \\
\hline & $\mathrm{CS}$ & 15 & 26,79 \\
\hline & TS & 2 & 3,57 \\
\hline & STS & 0 & 0,00 \\
\hline & Jumlah & 56 & 100 \\
\hline & Pesa & & \\
\hline \multirow{6}{*}{ Logo lembaga } & SS & 12 & 21,43 \\
\hline & $\mathrm{S}$ & 24 & 42,86 \\
\hline & CS & 16 & 28,57 \\
\hline & TS & 4 & 7,14 \\
\hline & STS & 0 & 0,00 \\
\hline & Jumlah & 56 & 100 \\
\hline \multirow{5}{*}{ Brosur } & SS & 10 & 17,86 \\
\hline & $\mathrm{S}$ & 23 & 41,07 \\
\hline & $\mathrm{CS}$ & 12 & 21,43 \\
\hline & TS & 1 & 1,79 \\
\hline & STS & 0 & 0,00 \\
\hline \multirow{6}{*}{ Alat peraga penyuluhan } & SS & 10 & 17,86 \\
\hline & $\mathrm{S}$ & 34 & 60,71 \\
\hline & $\mathrm{CS}$ & 12 & 21,43 \\
\hline & TS & 0 & 0,00 \\
\hline & STS & 0 & 0,00 \\
\hline & Jumlah & 56 & 100 \\
\hline
\end{tabular}

Keterangan : SS : Sangat Setuju, S: Setuju, CS: Cukup Setuju. TS : Tidak Setuju, STS : Sangat Tidak Setuju

Sumber: Data Olahan, 2017 


\section{Sikap Peserta Penyuluhan Program}

Sikap peserta penyuluhan program Keluarga Berencana Nasional Puskesmas Pembantu Cilendek Timur dapat diketahui melalui indikator-indikatornya, yaitu kognitif, afektif dan behavioral. Berdasarkan hasil penyebaran kuesioner terhadap 56 responden

\section{Keluarga Berencana Nasional}

yang merupakan peserta penyuluhan program Keluarga Berencana Nasional, dapat diketahui sikap peserta penyuluhan program Keluarga Berencana Nasional Puskesmas Pembantu Cilendek Timur, sebagai berikut :

\section{Tabel 2 Tanggapan Responden Mengenai Sikap Peserta Penyuluhan Program Keluarga Berencana Nasional}

\begin{tabular}{cllcc}
\hline Indikator & Jawaban & $\begin{array}{c}\text { F } \\
\text { (Orang) }\end{array}$ & $\begin{array}{c}\text { Persen } \\
(\mathbf{\%})\end{array}$ \\
Kognitif & SS & 18 & 32,14 \\
& S & 35 & 62,50 \\
& CS & 3 & 5,36 \\
& TS & 0 & 0,00 \\
& STS & 0 & 0,00 \\
Afektif & & Jumlah & $\mathbf{5 6}$ & $\mathbf{1 0 0}$ \\
& SS & & 21 & 37,50 \\
& S & 32 & 57,14 \\
& CS & 3 & 5,36 \\
& TS & 0 & 0,00 \\
& STS & 0 & 0,00 \\
& & Jumlah & 21 & $\mathbf{1 0 0}$ \\
& SS & 32 & 37,50 \\
& S & 2 & 57,14 \\
& CS & 1 & 3,57 \\
& TS & 0 & 1,79 \\
& STS & $\mathbf{5 6}$ & 0,00 \\
\hline
\end{tabular}

Keterangan : SS : Sangat Setuju, S: Setuju, CS: Cukup Setuju. TS : Tidak Setuju, STS : Sangat Tidak Setuju

Sumber: Data Olahan, 2017

\section{Hubungan Antara Pesan Penyuluhan Dengan Sikap Peserta Penyuluhan Program Keluarga Berencana Nasional}

Hubungan antara pesan penyuluhan dengan sikap peserta penyuluhan program Keluarga Berencana Nasional Puskesmas Pembantu Cilendek Timur dilakukan dengan menggunakan uji korelasi rank spearman. Sebagai hasil uji korelasinya disajikan dalam Tabel 3. 
Tabel 3 Nilai Hubungan antara Pesan Penyuluhan dengan Sikap Peserta Penyuluhan

\begin{tabular}{lccc}
\hline \multicolumn{1}{c}{ Pesan Penyuluhan } & \multicolumn{3}{c}{ Sikap Peserta Penyuluhan } \\
\cline { 2 - 4 } & Kognitif & Afektif & Behavioral \\
\hline Pesan yang diucapkan & & & \\
\hline Pengertian KB & $0,291^{*}$ & $0,271^{* *}$ & $0,300^{*}$ \\
Tujuan KB & 0,008 & $0,348^{* *}$ & $0,313^{*}$ \\
Manfaat KB & $-0,092$ & $0,625^{* *}$ & $-0,106$ \\
Jenis-jenis alat kontrasepsi & $-0,017$ & $0,525^{* *}$ & $-0,037$ \\
\hline Pesan pendukung (non & & & \\
verbal) & & & $0,265^{* *}$ \\
\hline Logo lembaga & 0,100 & $0,508^{* *}$ & $-0,083$ \\
\hline Brosur & $-0,155$ & 0,103 & $0,341^{*}$ \\
\hline Alat peraga penyuluhan & $-0,109$ & & \\
& & & \\
\hline
\end{tabular}

Berdasarkan hasil uji hubungan antara pesan penyuluhan dengan sikap peserta penyuluhan program Keluarga Berencana Nasional Puskesmas Pembantu Cilendek Timur, dapat diketahui bahwa pesan penyuluhan untuk indikator pesan yang diucapkan pada sub indikator tujuan $\mathrm{KB}$, manfaat $\mathrm{KB}$ dan jenis-jenis alat kontrasepsi mempunyai hubungan sangat nyata dengan pembentukan sikap afektif, sub indikator pengertian $\mathrm{KB}$ mempunyai hubungan nyata dengan sikap kognitif, afektif dan behavioral, dan sub indikator tujuan $\mathrm{KB}$ mempunyai hubungan nyata dengan sikap behavioral.

Temuan dari penelitian yang dilakukan, petugas penyuluh di dalam penyuluhan menyampaikan pesan berupa pesan yang disampaikan mengenai pengertian $\mathrm{KB}$, tujuan $\mathrm{KB}$, manfaat $\mathrm{KB}$, dan jenis-jenis alat kontrasepsi, serta pesan pendukung (non verbal) berupa logo lembaga, brosur dan alat peraga penyuluhan.

Keberhasilan penyuluhan program $\mathrm{KB}$ di dalamnya terkandung tanggungjawab yang harus dicapai. Tanggung jawab tersebut yaitu keberhasilan dari kegiatan penyuluhan berupa perubahan sikap, yaitu meliputi sikap kognitif, afektif, dan behavioral. Di dalam sebuah pertemuan penyuluhan mereka akan menyampaikan pesan berupa pengertian $\mathrm{KB}$, tujuan $\mathrm{KB}$, manfaat $\mathrm{KB}$, dan jenis-jenis alat kontrasepsi, serta pesan pendukung (non verbal) berupa logo lembaga, brosur dan alat peraga penyuluhan secara tegas dan berulangulang.

Di dalam setiap proses komunikasi pasti terdapat gangguan. Noise atau gangguan ini mengurangi keefektifan dari komunikasi yang dilakukan. Petugas penyuluh Program Kelurarga Berencana di dalam menjalankan tugasnya, mereka menghadapi beberapa hambatan. Hambatan tersebut berasal dari petugas sendiri dan juga dari luar. Hambatan yang berasal dari penyuluh adalah bahasa dan waktu. Kendala waktu sering menjadi hambatan di dalam memberikan penyuluhan terhadap masyarakat. Waktu kegiatan penyuluhan terkadang bersamaan dengan adanya kegiatan lain, sehingga mereka menjadi berhalangan untuk hadir. Menyikapi hal ini, petugas penyuluh biasanya dapat meminta petugas dari Puskesmas untuk menggantikannya memberikan penyuluhan. Hambatan eksternal yang sering dihadapi oleh petugas penyulu adalah audiens dan pemahaman mengenai program. Hambatan ini berasal dari masyarakat. Memberikan penyuluhan mengenai sebuah program kepada masyarakat tidak bisa berhasil dalam satu kali pertemuan. Petugas penyuluh harus melakukan penyuluhan beberapa kali untuk meyakinkan masyarakat supaya tertarik untuk 
mengadopsi program yang disarankan. Hambatan yang sering terjadi pada audiens adalah keluarga mereka menentang untuk mengikuti Program Keluarga Berencana. Penolakan yang dilakukan oleh masyarakat biasanya karena kesalahan pemahaman

\section{Implikasi Teoritis}

Sesuai pendapat Setiana (2005) proses komunikasi dalam penyuluhan selalu dikaitkan dengan tujuan untuk mengubah pengetahuan, pendapat, sikap, keterampilan, dan perilaku sasaran komunikasi, baik secara langsung atau tidak langsung, sehingga sasaran komunikasi akan berubah menuju ke arah lebih baik dengan cara mengikuti saran, gagasan, atau inovasi yang diajarkan.

Nasution (2009) menyatakan bahwa dalam melakukan penyuluhan, faktor penyampaian hal-hal yang disuluhkan memegang peranan yang penting. Berkaitan dengan penyuluhan KB yang akan dilakukan di Cilendek Timur, maka faktor yang akan disuluhkan merupakan hal penting, sehingga perlu direncanakan dengan matang agar isi pesan dapat dipahami hingga menimbulkan pemaknaan pada diri sasaran ke arah kognitif, afektif, atau behavior. Melalui desain visual atau cara penyampaian langsung isi pesan kepada sasaran penyuluhan, maka pesan penyuluhan perlu menggambarkan permasalahan yang relevan bagi sasaran. Pesertanya pun sesuai dengan target penyuluhan, dengan tujuan agar sasaran mampu memahami pemaknaan pesan, yang dilaksanakan melalui pendekatan langsung dan media pendukung seperti teks (materi) penyuluhan.

Dengan demikian akan diketahui bagaimana pengembangan pesan oleh komunikator pada proses penyuluhan sebagai bentuk sosialisasi dimungkinkan akan menimbulkan pemaknaan yang berbeda kepada komunikan sesuai dengan kondisi dan terhadap Program Keluarga Berencana. Ini terjadi karena mereka tidak mendapatkan informasi dari pihak yang ahli dibidangnya. Masyarakat terkadang hanya mendapatkan informasi dari saudara atau tetangga sehingga mendatangkan pemahaman yang salah.

situasi peserta penyuluhan (komunikan) pada ranah sikap seperti kognitif, afektif atau behavioral. Pada konteks pengembangan pesan dapat dilihat dari materi berikut permasalahan yang terkandung dalam materi penyuluhan, juga simbol-simbol pendukung secara non verbal dari pesan penyuluhan yang disampaikan pada saat penyuluhan. Efektivitas komunikasi dalam kegiatan penyuluhan dilihat dari sejauh mana kegiatan tersebut mampu mengubah sikap pesertanya. Sikap dalam hal ini berarti konstelasi komponen-komponen kognitif, afektif, dan behavioral yang saling berinteraksi dalam pemahaman atau pemaknaan awal saat sasaran penyuluhan menerima rangsangan dari objek isi pesan, sehingga berkembang ke arah perasaan dan berperilakunya terhadap suatu objek.

\section{Implikasi Praktis}

Hasil penelitian ini dilakukan sebagai masukan bagi penyuluh program KB sebagai ujung tombak di daerah, diharapkan harus mampu bekerja sesuai tugas dan fungsi seorang penyuluh program $\mathrm{KB}$, dimana penyuluh program $\mathrm{KB}$ harus memiliki wawasan dan kemampuan dalam berkomunikasi yang baik dengan masyarakat. Penyuluh program KB harus mampu menjadi seorang komunikator yang berperan mengantarkan pesan/informasi secara efektif agar masyarakat mampu memberikan efek yang baik. Selain itu, penyuluh program KB harus mampu menjalankan perannya secara maksimal agar terlaksananya program $\mathrm{KB}$ dengan baik. 
KESIMPULAN DAN IMPLEMENTASI

\section{Kesimpulan}

1. Pesan penyuluhan program Keluarga Berencana Nasional di Puskesmas Pembantu Cilendek Timur dapat diketahui melalui indikatorindikatornya, yaitu pesan yang diucapkan, yang meliputi pengertian $\mathrm{KB}$, tujuan $\mathrm{KB}$, manfaat $\mathrm{KB}$, dan jenisjenis alat kontrasepsi, serta pesan pendukung (non verbal), yang meliputi logo lembaga, brosur dan alat peraga penyuluhan. Dari hasil penelitian, diketahui bahwa untuk indikator pesan yang diucapkan, penyuluh program KB memberikan penjelasan mengenai pengertian $\mathrm{KB}$, tujuan $\mathrm{KB}$, manfaat $\mathrm{KB}$ dan jenis-jenis alat kontrasepsi dengan cara yang mudah dipahami, serta setelah mengikuti penyuluhan program $\mathrm{KB}$, pemahaman responden mengenai pengertian $\mathrm{KB}$, tujuan $\mathrm{KB}$, manfaat $\mathrm{KB}$ dan jenis-jenis alat kontrasepsi menjadi meningkat. Untuk indikator pesan pendukung (non verbal), diketahui bahwa tampilan logo lembaga dan brosur cukup menarik, arti dari logo lembaga cukup mudah dipahami oleh peserta penyuluhan, dengan adanya brosur yang diberikan saat penyuluhan memudahkan peserta penyuluhan untuk memahami mengenai program $\mathrm{KB}$, alat peraga yang disajikan pada saat penyuluhan cukup lengkap, serta dengan adanya alat peraga yang disajikan pada saat penyuluhan memudahkan peserta penyuluhan untuk memahami mengenai program KB.

2. Sikap peserta penyuluhan program Keluarga Berencana Nasional Puskesmas Pembantu Cilendek Timur dapat diketahui melalui indikatorindikatornya, yaitu kognitif, afektif dan behavioral. Dari hasil penelitian, diketahui bahwa pesan penyuluhan program KB Nasional oleh Puskesmas
Pembantu Cilendek Timur telah menimbulkan perubahan sikap pada peserta program, baik pada aspek kognitif, afektif maupun behavioral.

3. Untuk menguji hubungan antara pesan penyuluhan dengan sikap peserta penyuluhan program Keluarga Berencana Nasional Puskesmas Pembantu Cilendek Timur dilakukan dengan menggunakan uji korelasi rank spearman. Berdasarkan hasil pengujian, dapat diketahui bahwa untuk indikator pesan yang diucapkan dan pesan pendukung (non verbal) mempunyai hubungan nyata dengan sikap peserta penyuluhan. Dengan demikian, hipotesis penelitian yang menyatakan terdapat hubungan antara pesan penyuluhan dengan sikap peserta penyuluhan program Keluarga Berencana Nasional, dapat diterima.

\section{Implementasi}

1. Untuk lebih meningkatkan keberhasilan penyuluhan program KB Nasional, diharapkan pesan penyuluhan, baik pesan yang diucapkan maupun pesan pendukung (non verbal) lebih diperhatikan oleh penyuluh program KB.

2. Dalam pelaksanaan penyuluhan program KB, diharapkan penyuluh memperhatikan perubahan sikap peserta program, yaitu pada aspek kognitif, afektif serta behavioral

3. Penyuluh diharapkan memberikan materi penyuluhan yang mudah dipahami oleh peserta penyuluhan, sehingga peserta penyuluhan dapat mengetahui dengan pasti programprogram apa saja yang menjadi isi pesan atau informasi yang akan disampaikan oleh penyuluh.

4. Penyuluh diharapkan memperbaharui strategi penyuluhan yang digunakan, sehingga peserta penyuluhan tidak merasa jenuh dalam mengikuti kegiatan penyuluhan 


\section{DAFTAR PUSTAKA}

Azhari, Akyas. 2004. Psikologi Umum dan Perkembangan. Jakarta Selatan (ID): Teraju.

Azwar, Saifuddin. 2005. Sikap Manusia: Teori dan Pengukurannya. Yogyakarta (ID): Pustaka Pelajar.

Dinas Kependudukan dan Catatan Sipil Kota Bogor Tahun 2015 (diakses tanggal 25 Desember 2016)

Effendy, Onong Uchjana. 1989. Kamus Komunikasi. Bandung (ID): Mandar Maju.

Nasution, S. 2009. Sosiologi Pendidikan. Jakarta (ID): Bumi Aksara.

Nawawi, Hadari. 2003. Metode Penelitian Bidang Sosial. Yogyakarta (ID): UGM Press.

Notoatmodjo, Soekidjo, 2007. Promosi Kesehatan dan Ilmu Perilaku. Jakarta (ID): Rineka Cipta.

Prawirohardjo, Sarwono. 2003. Buku Panduan Praktis Pelayanan Kontrasepsi. Jakarta (ID): Yayasan Bina Pustaka.

Setiana. L. 2005. Teknik Penyuluhan DanPemberdayaan Masyarakat. Bogor (ID): Ghalia Indonesia.

Sugiyono. 2012. Metode Penelitian Kuantitatif, Kualitatif dan $R \& D$. Bandung (ID): Alfabeta.

Suwardikun, W. Didit. 2000. Merubah Citra Melalui Perubahan Logo. Bandung (ID): ITB Library.

\section{Sumber Internet :}

https://catherinemaname.wordpress.com diakses tanggal 25 Desember 2016).

Subejo. 2010. Dasar-dasar Penyuluhan. http://subejo.staff.ugm.ac.id. Diakses tanggal 25 Desember 2016. 
